Nathalie Josso
Rodolfo Rey

\section{ADRESSE}

$\mathrm{N}$. Josso : directeur de recherches à l'Inserm, directeur de l'U. 293 de l'Inserm. R. Rey : boursier, stagiaire post-doctoral, CONICET, Agentine Unité de recherches sur l'endocrinologie du développement, école normale supérieure, département de biologie, 1, rue Maurice-Arnoux, 92120 Montrouge, France.

\title{
La cellule de Sertoli, une cellule endocrine
}

Le développement de la virilité et de la fécondité masculine dépend de l'interaction coordonnée des diverses cellules contenues dans le testicule. Dans les tubes séminifères, les cellules de Sertoli, outre leur rôle de soutien des cellules germinales, ont une fonction endocrine importante. Très tôt dans le développement du fotus masculin, les cellules de Sertoli sécrètent l'hormone antimüllérienne (AMH) responsable de la régression des canaux de Müller. La sécrétion d'AMH persiste élevée jusqu'à la puberté, époque à laquelle elle disparaît, réglée négativement par la testostérone. Chez l'adulte, deux autres membres de la famille du TGF- $\beta$ sont sécrétés par les cellules de Sertoli et de Leydig, l'activine et l'inhibine. L'inhibine, dont la sécrétion par la cellule de Sertoli est activée par la FSH (follicle stimulating hormone), exerce un rétrocontrôle négatif sur la sécrétion hypophysaire de FSH. L'activine, à l'inverse, potentialise localement la stimulation par la LH (luteinizing hormone) de la synthèse des androgènes par les cellules de Leydig et stimule la sécrétion de FSH par l'hypophyse.

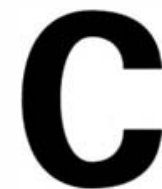
omme dans toute société bien organisée, chaque catégorie de cellules testiculaires a une fonction bien définie, complémentaire de celle de ses voisines. Les cellules de Leydig produisent les androgènes nécessaires à l'accomplissement de l'acte sexuel dont la fertilité est assurée par la présence de cellules germinales matures. Leurs compagnes dans les tubes séminifères, les cellules de Sertoli, jouent essentiellement un rôle d'assistance à la spermatogenèse. Leur base forme une barrière sélective entre le sérum et les cellules germinales évoluées, leur corps constitue un échafaudage qui maintient en place les clones de cel- lules germinales en voie de différenciation et absorbe les débris cellulaires qui en résultent, ainsi que les corps résiduels après libération des spermatozoïdes dans la lumière tubulaire. Enfin, leur pôle apical déverse dans le fluide tubulaire de nombreuses protéines qui interviennent localement dans le métabolisme intratesticulaire. Le rôle nourricier des cellules de Sertoli est traité en détail dans un autre article de ce numéro. Enfin, les tubes séminifères sont délimités par une paroi tubulaire constituée d'une membrane basale et de cellules péritubulaires concourant, avec les jonctions étanches entre les cellules de Sertoli, à la formation de la barrière hémato-testiculaire (figure 


\section{RÉFÉRENCES}

1. Hoeben E, Deboel L, Rombauts L, Heyns W, Verhoeven G. Different cells and cell lines produce factors that modulate Sertoli cell function. Mol Cell Endocrinol 1994 ; 101 : 263-75.

2. Maddocks S, Sharpe RM. The effects of sexual maturation and altered steroid synthesis on the production and route of secretion of inhibin- $\alpha$ from the rat testis. Endocrinology $1990 ; 126$ : 1541-50.

3. Rey RA, Campo SM, Bedecarrás P, Nagle $\mathrm{CA}$, Chemes HE. Is infancy a quiescent period of testicular development? Histological, morphometric, and functional study of the seminiferous tubules of the cebus monkey from birth to the end of puberty. J Clin Endocrinol Metab 1993; 76 : 1325-31.

4. Orth JM, Gunsalus GL, Lamperti AA. Evidence from Sertoli cell-depleted rats indicates that spermatid number in adults depends on numbers of Sertoli cells produced during perinatal development. Endocrinology 1988 ; 122 : 787-94.

5. Rabenandrasana C, Ramsohoye P. La clusterine : une nouvelle glycoprotéine protectrice de l'intégrité cellulaire? médecine/ sciences $1994 ; 10: 12-20$.

6. Rabinovici J, Goldsmith PC, Roberts VJ, Vaughan I, Vale W, Jaffe RB. Localization and secretion of inhibin/activin subunits in the human and subhuman primate fetal gonads. J Clin Endocrinol Metab 1991 ; 73 : 1141-9.

7. Burger HG, McLachlan RI, Bangah M, Quigg H, Findlay JK, Robertson DM, de Kretser DM, Warne GL, Werther GA, Hudson IL, Cook JJ, Fiedler R, Greco S, Yong ABW, Smith P. Serum inhibin concentrations rise throughout normal male and female puberty. I Clin Endocrinol Metab 1988 ; $67: 689-94$.

8. Josso N, Picard J, Vigier B, Tran D. L'hormone antimüllérienne. médecine/sciences 1987; $3: 444-52$.

9. Josso N, Cate RL, Picard JY, Vigier B, di Clemente N, Wilson C, Imbeaud S, Pepinsky RB, Guerrier D, Boussin L, Legeai L, Carré-Eusèbe $\mathrm{D}$. Anti-müllerian hormone, the Jost factor. In: Bardin CW, ed. Recent progress in homone research. Vol. 48. San Diego: Academic Press, 1993: 1-59.

10. Cate RL, Mattaliano RJ, Hession C, Tizard R, Farber NM, Cheung A, Ninfa EG, Frey AZ, Gash DJ, Chow EP, Fisher RA, Bertonis JM, Torres G, Wallner BP, Ramachandran KL, Ragin RC, Manganaro TF, MacLaughlin DT, Donahoe PK. Isolation of the bovine and human genes for müllerian inhibiting substance and expression of the human gene in animal cells. Cell $1986 ; 45$. 685-98.

11. Wilson CA, di Clemente N, Ehrenfels $C$ Pepinsky RB, Josso N, Vigier B, Cate RL Mullerian inhibiting substance requires its $\mathrm{N}$-terminal domain for maintenance of biological activity, a novel finding within the TGF- $\beta$ superfamily. Mol Endocrinol 1993 ; 7 :

1). En outre, les cellules péritubulaires produisent de nombreux facteurs de régulation locale [1].

Toutefois, le rôle des cellules de Sertoli ne se borne pas à materner les gamètes mâles dans l'univers clos du tube séminifère. Comme pour d'autres tissus, certains produits de sécrétion de ces cellules agissent également à distance de leur lieu de production, répondant ainsi à la définition d'une hormone. Avant la puberté et la formation contemporaine de la barrière hémato-testiculaire, leur diffusion ne rencontre aucun obstacle. Une fois scellées les jonctions étanches qui isolent le compartiment adluminal du tube séminifère, la sécrétion basale gagne plus facilement la circulation sanguine et peut atteindre des tissus à distance. La sécrétion apicale alimente notamment le fluide tubulaire et celui du rete testis, bien qu'elle puisse également être réabsorbée à ce niveau et passer ainsi dans la circulation sanguine (figure 1). La plupart des protéines sécrétées par les cellules de Sertoli le sont à la fois dans le sang et dans les tubes séminifères [2], même si leur rôle est purement local. Les véritables hormones produites par les cellules de Sertoli, celles qui jouent un rôle physiologique en dehors du testicule, sont relativement peu nombreuses. Les plus importantes appartiennent à la famille du transforming growth factor

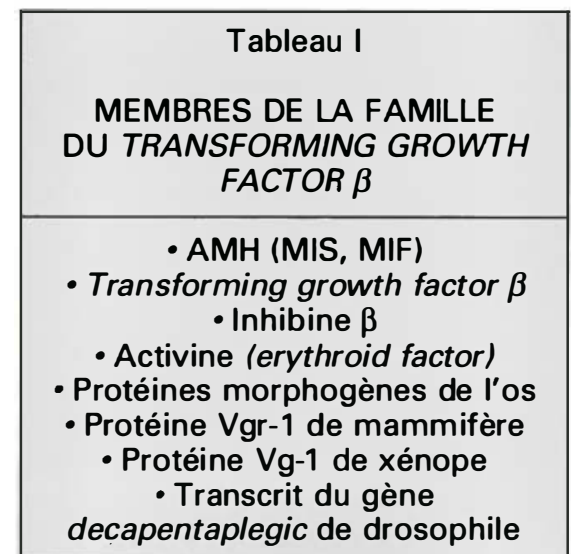

Dans l'ensemble, ils jouent un rôle dans les pro cessus de différenciation et de croissance cellulaire. Certains des facteurs identifiés chez la dro sophile et Xenopus laevis ont des équivalents chez les vertébrés supérieurs : ainsi les bone morphogenic factors des mammifères sont les homologues du facteur décapentaplégique, le produit d'un gène homéotique chez la drosophile. AMH : hormone antimüllérienne ; MIS : müllerian inhibiting substance ; MIF : müllerian inhibiting factor. $\beta$ (TGF- $\beta$ ), une famille de protéines intervenant dans la croissance et la différenciation (Tableau I). Le type d'hormone produit dépend essentiellement du degré de maturation de la cellule de Sertoli.

\section{La cellule de Sertoli immature}

Les premières cellules de Sertoli se différencient chez le fœetus avant même la formation des tubes séminifères, ce sont des cellules épithéliales avec des noyaux globulaires lisses et un cytoplasme clair et abondant. Elles se divisent activement jusqu'à la puberté [3], l'efficacité de la spermatogenèse chez l'adulte est en relation directe avec le nombre de cellules de Sertoli préexistantes [4].

Les cellules de Sertoli synthétisent de nombreuses glycoprotéines, dont la clusterine [5] ou sulfated glycoprotein2, l'androgen binding protein (ABP), l'activateur de plasminogène, la transferrine et la céruloplasmine, pour ne citer que les mieux connues. Nous ne nous intéresserons ici qu'à celles capables de jouer un rôle en dehors du testicule, et qui méritent de ce fait le nom de facteur endocrine, même si la plupart ont également une fonction intratesticulaire de type autocrine ou paracrine. Les trois hormones produites par la cellule de Sertoli, l'hormone antimüllérienne (AMH), l'inhibine et l'activine, font partie de la famille du TGF- $\beta$ (Tableau I), qui compte également parmi ses membres des facteurs intervenant dans le développement de Drosophila et de Xenopus laevis. L'AMH est produite essentiellement par la cellule de Sertoli immature. L'inhibine et l'activine, bien que synthétisées déjà chez le fotus [6], sont essentiellement, du moins dans l'espèce humaine, des produits de la cellule de Sertoli adulte [7] et seront considérées à ce chapitre.

\section{L'hormone antimüllérienne}

C'est en 1953 qu'Alfred Jost, grâce à des expériences de chirurgie foetale, émit l'hypothèse que le testicule fotal sécrète deux hormones distinctes agissant sur la différenciation sexuelle [8]. La première, la testostérone, était bien connue depuis que Bouin et Ancel avaient montré que les cellules de Leydig fotales ont, comme 


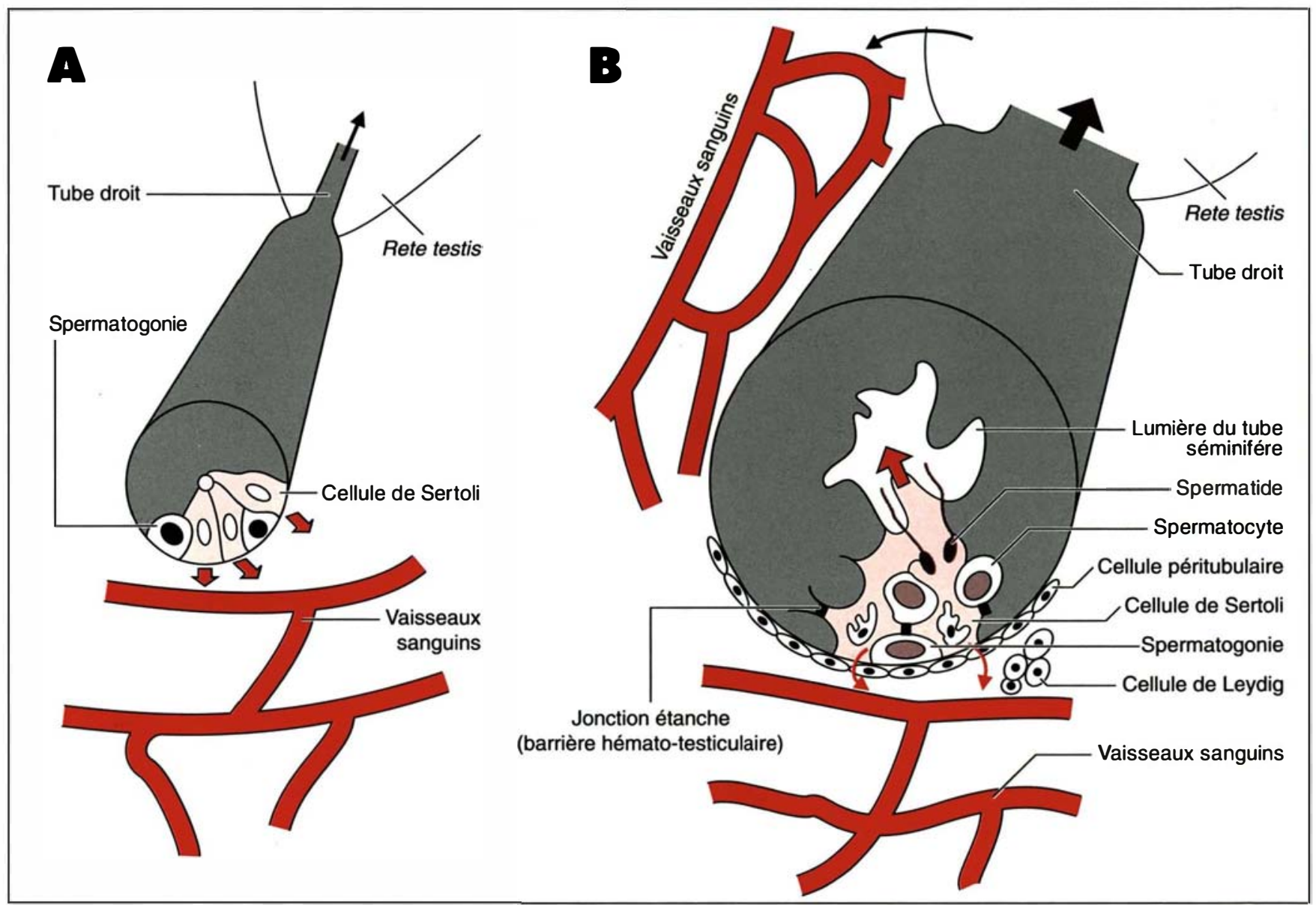

Figure 1. Influence de la maturation pubertaire sur la sécrétion des cellules de Sertoli. Avant la puberté (A), la barrière hémato-testiculaire n'est pas encore formée, et les protéines sécrétées par la cellule de Sertoli se répartissent sans contrainte entre le compartiment vasculaire et le liquide intra-tubulaire. Après la puberté (B), des jonctions étanches entre les cellules de Sertoli se développent, délimitant un compartiment basal, en relation avec les vaisseaux sanguins, et un compartiment adluminal, dont le contenu se déverse dans le liquide du rete testis. A la puberté, la proportion des protéines qui se dirigent vers le compartiment adluminal augmente beaucoup, mais une partie importante est réabsorbée par les vaisseaux au niveau du rete testis.

chez l'adulte, une activité endocrine. La testostérone masculinise les organes génitaux externes et le sinus urogénital mais elle est incapable de faire régresser les canaux de Müller, les ébauches de l'utérus et des trompes chez la femelle, alors qu'un fragment de testicule fotal, greffé en position ovarienne ou mis au contact d'un tractus génital femelle en culture organotypique, inhibe leur développement. Jost émit alors l'hypothèse que le testicule fotal produit une hormone distincte de la testostérone et responsable de la régression des canaux de Müller chez le fotus mâle. L'activité antimüllérienne du testicule fotal est conservée après élimina- tion par microdissection du tissu interstitiel et destruction par irradiation des cellules germinales, ce qui suggérait qu'elle était d'origine sertolienne [9]. La preuve définitive fut apportée en 1982, date à laquelle on a pu disposer d'anticorps monoclonaux contre l'AMH bovine. L'étude par immunocytochimie de testicule fotal de veau a permis de localiser l'hormone au niveau du réticulum endoplasmique rugueux des cellules de Sertoli. L'AMH est également produite par les cellules somatiques de l'ovaire, les cellules de la granulosa, mais en faible quantité et seulement dans les follicules en croissance [9]. Aucun autre tissu ne produit d'AMH.
L'AMH, également appelée Müllerian inhibiting substance (MIS) ou factor (MIF), est une glycoprotéine homodimère, très hydrophobe, dont les sous-unités de $70 \mathrm{kDa}$ sont unies par des ponts disulfure. Le gène de 2,8 kilobases codant pour la protéine humaine et localisé sur le chromosome 19 a été cloné en 1986 [10]. L'analogie avec les autres membres de la famille du TGF- $\beta$ ne porte que sur la partie 3' du cinquième et dernier exon. A l'inverse des autres protéines de la famille, dont la partie active est clivée directement par les cellules productrices, l'AMH circule sous sa forme pro-hormonale non clivée. Toutefois, elle possède, comme ses 


\section{RÉFÉRENCES}

12. di Clemente $\mathrm{N}$, Wilson CA, Faure $\mathrm{E}$ Boussin L, Carmillo P, Tizard R, Picard JY, Vigier B, Josso N, Cate RL. Cloning, expression and alternative splicing of the receptor for anti-müllerian hormone. Mol Endocinol $1994 ; 8: 1006-20$.

13. Josso N, Lamarre I, Picard JY, Berta P, Davies N, Morichon N, Peschanski M, Jeny R. Anti-müllerian hormone in early human development. Early Hum Dev 1993 ; 33 : 919 .

14. Münsterberg A, Lovell-Badge R. Expression of the mouse anti-müllerian hormone gene suggests a role in both male and female sex differentiation. Development 1991 ; 113: 613-24.

15. Shen WH, Moore CCD, Ikeda Y, Parker KL, Ingraham HA. Nuclear receptor steroidogenic factor 1 regulates the mullerian inhibiting substance gene : a link to the sex determination cascade. Cell 1994 ; 77 : 65161 .

16. Saez J, Durand P. Rôle du facteur SF-1 dans le développement des gonades et des surrénales, et dans la stéroidogenèse. médecine/sciences $1994 ; 10: 1315-7$.

17. Rey R, Lordereau-Richard I, Carel JC, Barbet P, Cate RL, Roger M, Chaussain JL, Josso N. Anti-müllerian hormone and testosterone serum levels are inversely related during normal and precocious pubertal development. J Clin Endocrinol Metab 1993 ; 77 : $1220-6$.

18. Rey R, Mebarki F, Forest MG, Mowszowicz I, Cate RL, Morel Y, Chaussain JL, Josso N. Anti-müllerian hormone in children with androgen insensitivity. J Clin Endocrinol Metab $1994 ; 79$ : 960-4.

19. Baarends WM, van Helmond M[L, van der Schoot PCJM, Hoogerbrugge JW, de Winter JP, Uilenbroek JTJ, Karels B, Wilming LG, Meijers JHC, Themmen APN, Grootegoed JA. A novel member of the transmembrane serine/threonine kinase receptor family is specifically expressed in the gonads and in mesenchymal cells adjacent to the müllerian duct. Development 1994 ; $120: 189-97$.

20. Behringer RR, Finegold MI, Cate RL. Müllerian-inhibiting substance function during mammalian sexual development. Cell $1994 ; 79: 415-25$.

21. Zhou BY, Watts LM, Hutson JM. Germ cell development in neonatal mouse testes in vitro requires mullerian inhibiting substance. J Urol 1993 ; 150 (2 Part 2) : 613-6.

22. Behringer RR, Cate RL, Froelick GJ, Palmiter RD, Brinster RL. Abnormal sexual development in transgenic mice chronically expressing müllerian inhibiting substance. cousins, un site de clivage protéolytique 110 acides aminés en amont de son extrémité C-terminale, l'activité biologique réside sur le fragment $\mathrm{C}$ terminal [11]. Une protéine dont le site protéolytique a été détruit par mutagenèse dirigée est dépourvue d'activité biologique. Toutefois, l'activité du fragment C-terminal est potentialisée par la présence du fragment N-terminal et non inhibée, comme c'est le cas pour le TGF- $\beta$. Il est probable que le clivage protéolytique a lieu au niveau de cellules cibles spécialisées, équipées des enzymes appropriées car, pour obtenir une liaison de l'AMH à son récepteur exprimé dans une lignée cellulaire recombinante, il est nécessaire de la pré-cliver par la plasmine [12] (figure 2).

Bien qu'elle soit la première protéine identifiée produite par les cellules de Sertoli, l'AMH n'est synthétisée que lorsque la différenciation testiculaire s'est déjà manifestée par la formation de tubes séminifères, c'est-à-dire à environ huit semaines chez le fotus humain [13]. La production d'AMH se poursuit pendant toute la vie fotale et décroît ensuite jusqu'à la puberté (figure 3). En clinique humaine, le dosage sérique de l'AMH est un ex- cellent marqueur de la présence et de la valeur fonctionnelle du testicule prépubertaire, d'autant plus que la production d'AMH par les cellules de Sertoli n'exige pas une stimulation préalable par l'hCG (human chorionic gonadotropin). Comme, avant la puberté, le testicule est le seul organe à produire de l'AMH en quantité dosable dans le sérum, le fait de détecter de l'AMH circulante, même à faible concentration, suffit à prouver l'existence de cellules de Sertoli fonctionnelles et, par conséquent, la présence de tissu testiculaire. Le dosage d'AMH peut également être utile en médecine prénatale, afin d'établir l'existence de tissu testiculaire chez un fœtus XX [13].

L'ontogenèse de la production d'AMH est très différente dans les deux sexes. Alors que les cellules de Sertoli synthétisent des quantités importantes d'AMH dès la différenciation testiculaire et réduisent leur production à la puberté, les cellules de la granulosa en produisent beaucoup moins, mais de façon constante, pendant toute la période de maturité sexuelle. Dans la mesure où l'AMH n'est exprimée précocement que dans le testicule, il est logique de penser que l'activation de son gène

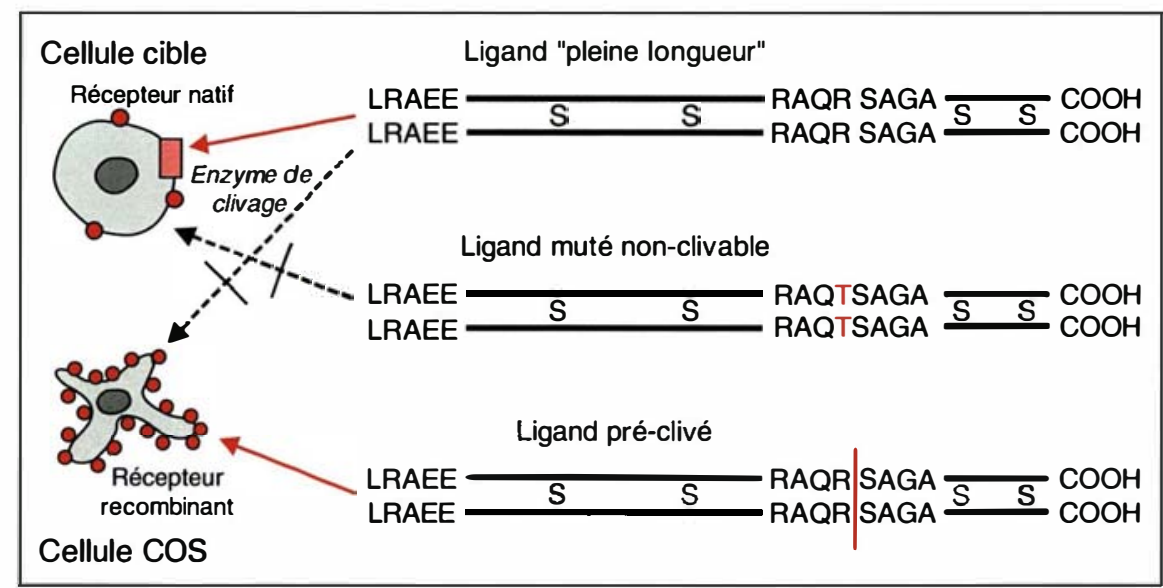

Figure 2. Rôle de l'enzyme de clivage dans la liaison de l'AMH à son récepteur. Celle-ci est sans doute présente sur la membrane des cellules cibles de I'AMH, car l'hormone "pleine longueur" y est active, à condition toutefois qu'elle soit clivable. Une protéine dont l'arginine a été remplacée par une thréonine (ligand muté non clivable) perd son activité biologique. En outre, seule une hormone clivée par la plasmine (ligand pré-clivé) peut se lier à un récepteur recombinant (points rouges) exprimé dans des cellules COS, qui ne possèdent vraisemblablement pas l'enzyme de clivage (rectangle rose). Les flèches rouges indiquent une liaison possible, les flèches en pointillés barrées signifient que la liaison ne peut être obtenue. 
fait partie de la "cascade transcriptionnelle" déclenchée par l'expression du gène $S R Y$, le facteur de détermination testiculaire. Toutefois, il ne semble pas que SRY soit directement responsable de l'activation du gène, ne serait-ce que parce que le délai qui sépare l'expression de $S R Y$ et du gène de l'AMH dans le testicule est trop important - deux jours chez la souris [14]. SRY se lie à une séquence contenue dans le promoteur du gène de l'AMH, CCTTGA, mais de façon non spécifique. En revanche, le récepteur nucléaire SF-1 (steroidogenic factor 1), qui active plusieurs gènes codant pour des enzymes de la stéroïdogenèse dans le testicule et dans l'ovaire, se lie à une séquence 5'-CCAAGGTCA, située environ 200 bases en amont de la partie codante du gène de l'AMH, et active la transcription de celui-ci dans des cellules de Sertoli immatures de rat. Ce facteur de transcription, qui est exprimé dans le testicule mais non l'ovaire foetal, joue un rôle important dans la différenciation de la gonade. Il servirait en quelque sorte d'intermédiaire entre le gène $S R Y$ et celui de l'AMH, à condition que d'autres facteurs sertoliens, encore non identifiés, soient également présents. En

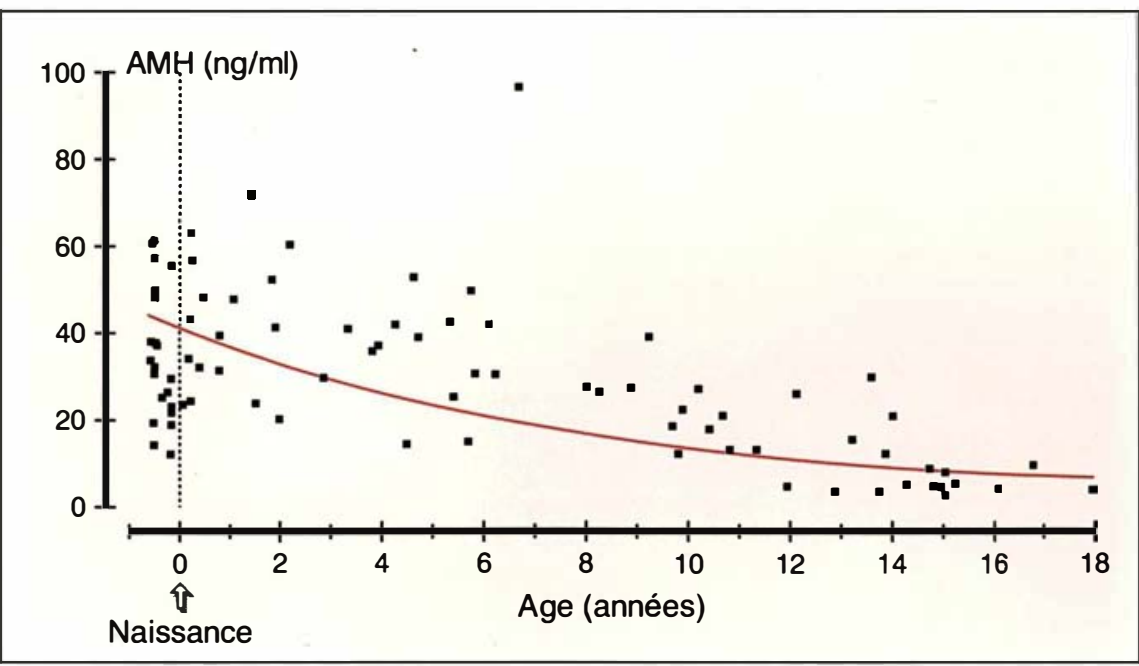

Figure 3. Ontogenèse de l'AMH humaine chez le garcon normal. L'AMH sérique est mesurée par un dosage ELISA utilisant des anticorps dirigés spécifiquement contre I'AMH humaine.

$m / s n^{\circ} 4$, vol. 11, avril 95 effet, l'expression de l'AMH n'a pu être induite dans des lignées cellulaires établies, comme les cellules HeLa, transfectées avec SF-1 $(\mathrm{m} / \mathrm{s}$ $n^{\circ} 10$, vol. $\left.10, p .1054\right)[15,16]$.

Dès la puberté, la cellule de Sertoli ramène son niveau de production d'AMH au niveau de celui des cellules de la granulosa. L'effondrement de la concentration sérique de l'AMH est dû en partie à la formation de la barrière hémato-testiculaire car on trouve une quantité significative d'AMH dans le liquide du rete testis de l'adulte. Toutefois, ce n'est pas la seule explication car l'AMH sérique diminue avant la formation de la barrière hémato-testiculaire et la baisse de l'expression peut être mise en évidence par des techniques qui mesurent directement la protéine ou son messager au niveau cellulaire. Des investigations récentes ont démontré qu'à la puberté, l'expression de l'AMH est inhibée par la testostérone [17]. La concentration d'AMH sérique reste relativement élevée chez les sujets souffrant d'un retard pubertaire idiopathique; en revanche, elle diminue chez les malades atteints de puberté précoce, que celle-ci soit liée à une activation prématurée de l'axe hypothalamo-hycellule de Sertoli induite par les androgènes. Cette maturation se traduit par des modifications morphologiques et biochimiques frappantes, qui ont pour conséquence de permettre à la cellule de Sertoli de jouer son rôle d'"assistance à la spermatogenèse ". L'AMH n'étant alors plus indispensable, sa production est en veilleuse au profit de protéines plus utiles.

A ce propos, l'AMH joue-t-elle un rôle physiologique dans le testicule à un moment quelconque du développement ? On pourrait le supposer, puisqu'elle continue à être produite par la cellule de Sertoli immature bien après la régression complète des canaux de Müller (figure 3). La présence du récepteur de l'AMH dans les cellules de Sertoli jusqu'à la puberté est un indice de plus en faveur d'un rôle paracrine ou autocrine de l'AMH. Le récepteur de l'AMH a été cloné récemment à partir d'ovaires de foetus de lapin [12] et également à partir d'une banque d'ADNc préparée à 


\section{RÉFÉRENCES}

23. Welsh MJ, Wiebe JP. Sertoli cells from immature rats: in vitro stimulation of steroid metabolism by FSH. Biochem Biophys Res Commun 1976 ; 69 : 936-41.

24. Dorrington JH, Armstrong DT. Folliclestimulating hormone stimulates estradiol17beta synthesis in cultured cells. Proc Natl Acad Sci USA 1975 ; 72 : 2677-81.

25. Papadopoulos V, Jia MC, Culty M, Hall PF, Dym M. Rat Sertoli cell aromatase cytochrome-P450-regulation by cell culture conditions and relationship to the state of cell differentiation. In Vitro Cell Dev Biol Animal 1993 ; 29A : 943-9.

26. Nakhla AM, Mather JP, Jänne OA, Bardin CW. Estrogen and androgen receptor in Sertoli, Leydig, myoid, and epithelial cells: effect of time in culture and cell density. Endocrinology 1984 ; 115 : 121-8.

27. Ying SY. Inhibins, activins and follistatins : gonadal proteins modulating the secretion of follicle-stimulating hormone. $E n$ door Rev 1988 ; 9 : $267-93$.

28. Schneyer A, Mason A, Burton L, Ziegner $\mathrm{J}$, Crowley W. Immunoreactive inhibin alpha subunit in human serum : implications for radioimmunoassay. I Clin Endocrinol $\mathrm{Me}$ tab $1990 ; 70: 1208-12$.

29. Steinberger A, Steinberger E. Secretion of an FSH-inhibiting factor by cultured Sertoli cells. Endocrinology 1976 ; 99 : 918.

30. Meunier H, Rivier C, Evans RM, Vale W Gonadal and extragonadal expression of in hibin alpha, beta $A$ and beta $B$ subunits in various tissues predicts diverse functions. Proc Natl Acad Sci USA 1988 ; 85 : 247-51.

31. Keinan D, Madigan MB, Bardin CW Chen CC. Expression and regulation of tes ticular inhibin $\alpha$-subunit gene in vivo and in vitro. Mol Endocrinol 1989 ; 3 : 29-35.

32. Burger HG, Yamada Y, Bangah ML, Mc Cloud PI, Warne GL. Serum gonadotropin, sex steroid, and immunoreactive inhibin levels in the first two years of life. J Clin Endo crinol Metab 1991 ; 72 : 682-6.

33. Robertson DM, Foulds LM, Leversha L, Morgan FI, Hearn MTW, Burger HG, Wettenhall REH, de Kretser DM. Isolation of inhibin from bovine follicular fluid. Biochem Biophys Res Commun 1985 ; 126 : 220-6.

34. Le Gac F, de Kretser DM. Inhibin production by Sertoli cell cultures. Mol Cell Endocrinol $1982 ; 28$ : 487-98.

35. Vale W, Bilezikjian LM, Rivier C. Reproductive and other roles of inhibins and activins. In Knobil E, Neill JD, eds. The physiolo gy of reproduction, 2nd ed. New-York : Raven Press, 1994: 1861-78.

36. Hsueh AJW, Dahl KD, Vaughan I, Tucker E, Rivier J, Bardin CW, Vale W. Heterodimers and homodimers of inhibin subunits have different paracrine action in the modulation of luteinizing hormone-stimulated androgen biosynthesis. Proc Natl Acad Sci

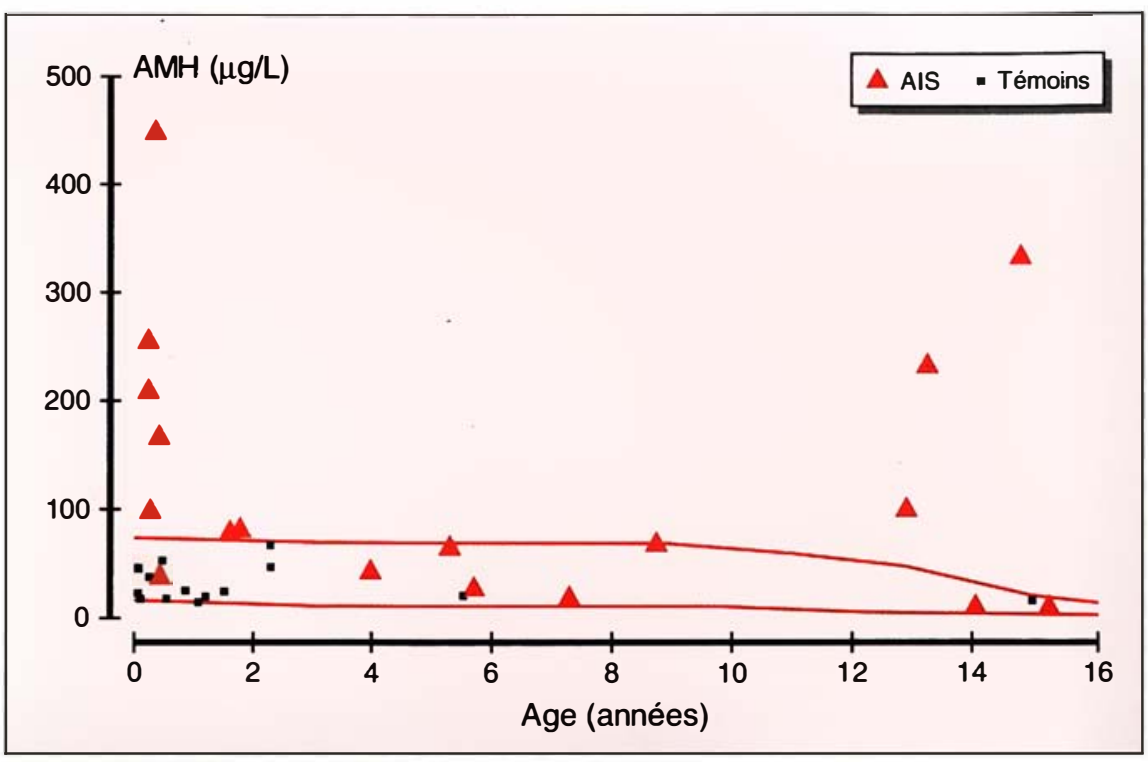

Figure 4. Concentration de l'AMH sérique chez des sujets atteints d'insensibilité aux androgènes (AlS) et chez des sujets témoins souffrant de pseudohermaphrodismes masculins d'autre origine. Adapté de Rey et al. [18].

partir de cellules de Sertoli de rat immature [19]. Il s'agit d'une sérinethréonine kinase avec un seul domaine transmembranaire, semblable aux récepteurs de l'activine et du TGF- $\beta$. Ce récepteur est exprimé autour du canal de Müller, dans les cellules de la granulosa mais également dans les cellules de Sertoli immatures. Parmi les rôles qui lui ont été proposés, la théorie selon laquelle l'AMH favoriserait la descente testiculaire a actuellement peu d'adeptes. Chez la souris, l'inactivation du gène de l'AMH par recombinaison homologue n'entrave ni la descente testiculaire ni la production de spermatozoïdes féconds, mais l'utérus présent chez ces mâles empêche la migration des spermatozoïdes [20]. Chez l'homme, la cryptorchidie fréquente chez les sujets atteints d'un déficit sélectif en AMH semble due tout simplement à un freinage de la descente testiculaire par les dérivés müllériens solidement amarrés dans le petit bassin. D'autres hypothèses restent à l'ordre du jour. L'AMH pourrait jouer un rôle indirect dans la différenciation testiculaire en s'opposant à la production d'œestrogènes du fait de son activité antiaromatase [9]. Après la naissance, elle pourrait favoriser la prolifération des gonocytes primordiaux [21] et jouer un rôle inhibiteur de la stéroïdogenèse. Des souris transgéniques pour le gène de l'AMH placé sous le contrôle d'un promoteur ubiquitaire et qui, de ce fait, produisent une quantité d'AMH environ cent fois supérieure à la normale, sont incomplètement masculinisées [22] alors que d'autres, dont le gène de l'AMH a été inactivé par recombinaison homologue, développent des tumeurs leydigiennes [20].

\section{Stéroïdogenèse}

Après la puberté, la cellule de Leydig, équipée des enzymes nécessaires pour synthétiser la testostérone à partir de cholestérol, est la principale source d'androgènes. Toutefois, les cellules de Sertoli possèdent les enzymes nécessaires à la transformation de précurseurs leydigiens, tels que la progestérone ou l'androstènedione, pour produire de la testostérone. La capacité des cellules de Sertoli à produire des androgènes est plus marquée avant la puberté, et stimulée par la FSH (follicle stimulating hormone) plutôt que par la LH, ce qui la distingue de la stéroïdogenèse des cellules de Leydig [23].

Les cellules de Sertoli immatures sont le siège d'une activité aromatase 
intense, qui leur permet de synthétiser des quantités importantes d'œstradiol à partir de précurseurs androgéniques fournis par la cellule de Leydig [24]. L'activité aromatase des cellules de Sertoli est inversement proportionnelle à leur état de différenciation [25].

La cellule de Sertoli est également une cible privilégiée de la testostérone dont elle exprime le récepteur [26] et qui, en coopération avec la FSH, modifie profondément sa morphologie et sa fonction. La cellule de Sertoli sert d'intermédiaire obligé entre la cellule de Leydig et les cellules germinales, qui dépendent de la testostérone pour leur maturation spermatogénétique bien qu'elles n'en expriment pas elles-mêmes le récepteur.

\section{La cellule de Sertoli adulte}

Pour comprendre l'étendue des transformations subies par la cellule de Sertoli au moment de la puberté, il suffit de la regarder! Alors que les cellules immatures, petites, rondes, empilées dans le désordre dans le tube séminifère, n'attirent pas particulièrement l'attention, les cellules adultes s'élevant comme une haute rangée d'arbres au-dessus de la membrane basale, tendant de nombreux embranchements vers les cellules germinales et servant de tremplin aux spermatozoïdes enfoncés à leur sommet, ne peuvent être confondues avec aucun autre type cellulaire ( $f i g u-$ re 5).

La sécrétion locale et endocrine de la cellule de Sertoli subit de profondes modifications au moment de la puberté. La production de l'AMH va s'estomper, alors que sera réactivée la sécrétion de facteurs dépendants de la FSH et de la testostérone, aussi bien à partir du pôle basal, vers le sérum, que du pôle apical, vers le liquide du rete testis. La polarisation apicale s'accentue, faisant passer de $60 \%$ à $95 \%$ la proportion d'inhibine $\alpha$ sécrétée dans la lumière du tube séminifère, mais une part importante est

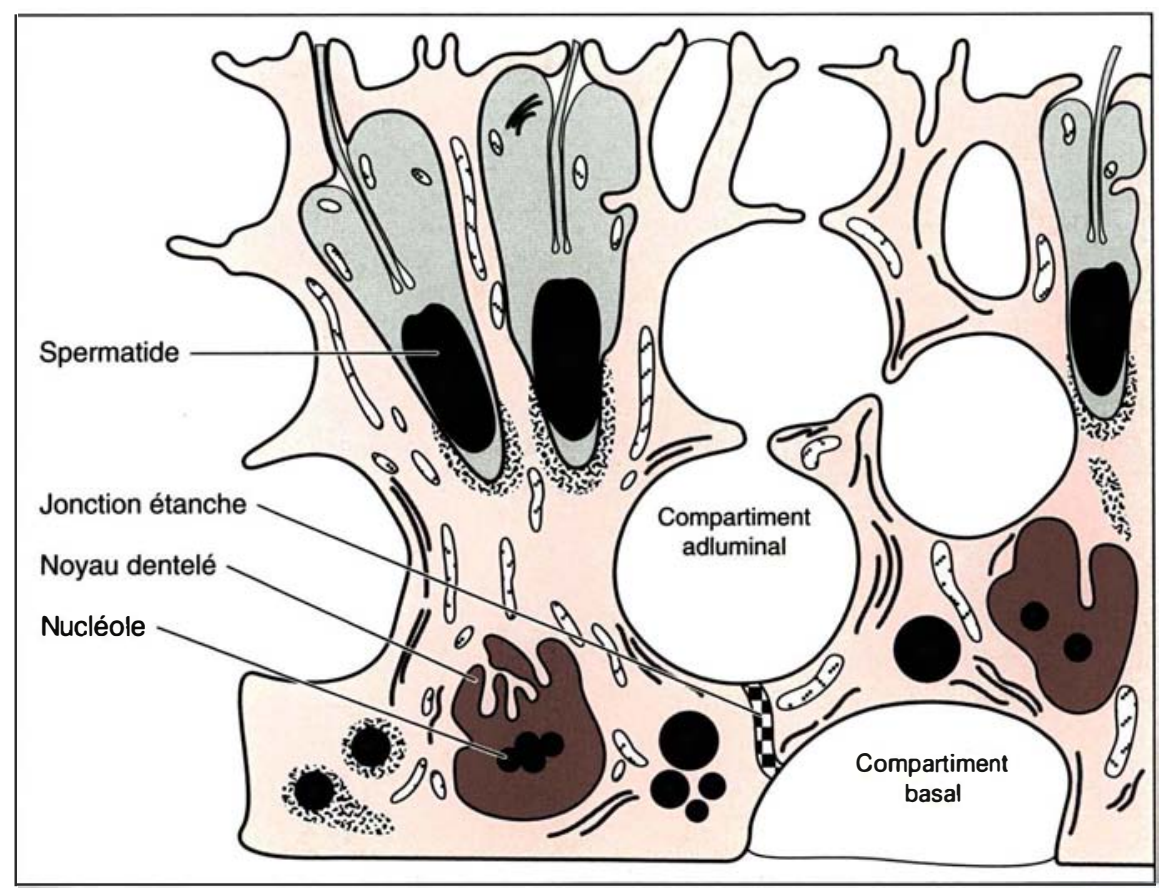

Figure 5. Diagramme d'une cellule de Sertoli adulte. La division entre compartiment basal, occupé par les spermatogonies, et compartiment adluminal, occupé par les cellules en méiose et les spermatides, est provoquée par la mise en place de jonctions étanches entre les cellules de Sertoli. Noter le noyau dentelé, le nucléole apparent, et surtout la forme ramifiée, très caractéristique, du cytoplasme (selon Fawcett [48]). ensuite réabsorbée à partir du rete testis [2]. Ainsi, la distinction entre "hormones" et "facteurs locaux" est-elle rendue très difficile, d'autant plus que la plupart des hormones sertoliennes jouent également un rôle régulateur intratesticulaire. Nous restreindrons notre étude à l'inhibine et à l'activine, dont le rôle endocrine est incontestable au vu de leur effet sur la sécrétion hypophysaire $(\mathrm{m} / \mathrm{s}$ $n^{\circ} 8$, vol. 2, p. 466).

\section{L'inhibine}

L'inhibine est une hormone glycoprotéique, appartenant comme l'AMH à la famille du TGF- $\beta$. Elle est formée de deux sous-unités différentes, $\alpha$ et $\beta$. Comme c'est le cas pour tous les membres de la famille du TGF- $\beta$, la protéine mûre résulte du clivage d'un précurseur environ 110 acides aminés en amont de l'extrémité C terminale.

Trois gènes codant pour des précurseurs des sous-unités de l'inhibine ont été isolés, un pour la sous-unité $\alpha$ et deux pour la sous-unité $\beta, \beta_{\mathrm{A}}$ et $\beta_{\mathrm{B}}$ dont les produits présentent environ $85 \%$ d'analogie [27]. Il existe donc deux formes d'inhibine $\alpha \beta_{A}$ et $\alpha \beta_{B}$ possédant une activité biologique identique (figure 6). Ces gènes sont réglés de façon indépendante et exprimés de façon très variable dans différents types cellulaires, gonadiques ou non. En particulier, dans le testicule, la sous-unité $\beta_{\mathrm{A}}$ est relativement peu abondante alors que la sous-unité $\alpha$ est exprimée en excès, ce qui favorise la formation d'inhibine par rapport à l'activine, qui est formée de deux sous-unités $\beta$ (figure 6). Cependant, cela peut entraîner des problèmes de spécificité dans le dosage radioimmunologique. Certains antisérums, dirigés contre des épitopes de la sous-unité $\alpha$-intéressants dans la mesure où ils ne reconnaissent pas l'activine - interagissent avec des formes aberrantes de la sous-unité $\alpha$ [28], dont l'activité biologique diffère de celle de l'inhibine. Ces protéines aberrantes ont été purifiées à partir de liquide folliculaire et de milieu de culture de cellules de Sertoli. L' $\alpha$ N est composée du fragment $\mathrm{N}$-terminal du précurseur de la sous-unité $\alpha$ et le pro- $\alpha \mathrm{C}$ est un dimère du fragment pro suivi du fragment C-terminal (figure 7). Dans l'ensemble, le dosage radio-immunologi- 


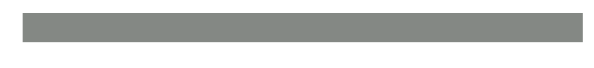

\section{RÉFÉRENCES}

37. Matzuk MM, Finegold MJ, Su JGJ, Hsueh AJW, Bradley A. Alpha-inhibin is a tumour-suppressor gene with gonadal specificity in mice. Nature $1992 ; 360: 313-9$.

38. Shikone T, Matzuk MM, Perlas E, Finegold MJ, Lewis KA, Vale W, Bradley A, Hsueh AJW. Characterization of gonadal sex cord-stromal tumor cell lines from inhibin-alpha and p53-deficient mice: the role of activin as an autocrine growth factor. $\mathrm{Mol}$ Endocrinol $1994 ; 8: 983-95$.

39. Feng ZM, Bardin CW, Chen CLC. Characterization and regulation of testicular inhibin $\beta$-subunit mRNA. Mol Endocrinol 1989; $3: 939-48$.

40. Skinner MK, McLachlan RI, Bremner WJ. Stimulation of Sertoli cell inhibin secretion by the testicular paracrine factor PModS. Mol Cell Endocrinol $1989 ; 66$ : 23949.

41. Pineau C, Sharpe RM, Saunders PTK, Gerard N, Jegou B. Regulation of Sertoli cell inhibin production and of inhibin alpha-subunit messenger RNA levels by specific germ cell types. Mol Cell Endocrinol 1990 ; $72: 13-22$.

42. Lee W, Mason AJ, Schwall R, Szonyi E Mather JP. Secretion of activin by interstitial cells in the testis. Science $1989 ; 243: 396-7$.

43. De Winter JP, Vanderstichele HMI, Timmerman MA, Blok LJ, Themmen APN, De Jong FH. Activin is produced by rat Sertoli cells in vitro and can act as an autocrine regulator of Sertoli cell function. Endocrinology $1993 ; 132$ : 975-82

44. Cameron VA, Nishimura E, Mathews LS Lewis KA, Sawchenko PE, Vale WW. Hybridization histochemical localization of activin receptor subtypes in rat brain, pituitary ovary, and testis. Endocrinology $1994 ; 134$ : 799-808.

45. Lin T, Calkins JH, Morris PL, Vale $\mathrm{W}$ Bardin CW. Regulation of Leydig cell function in primary culture by inhibin and activin. Endocrinology 1989 ; $125: 213440$.

46. Hakovirta H, Kaipia A, Soder O, Paryinen $M$. Effects of activin- $\alpha$, inhibin- $\alpha$, and transforming growth factor-beta-1 on stagespecific deoxyribonucleic acid synthesis during rat seminiferous epithelial cycle. Endocrinology 1993 ; 133 : 16648 .

47. Thomsen G, Woolf T, Whitman M, Sokol S, Vaughan J, Vale W, Melton DA. Activins are expressed early in Xenopus embryogenesis and can induce axial mesoderm and anterior structures. Cell $1990 ; 63: 485$ 93.

48. Fawcett DW. Ultrastructure and function of the Sertoli cell: In Greep RO, Hamilton DW, eds. Male eeproductive system. Be-

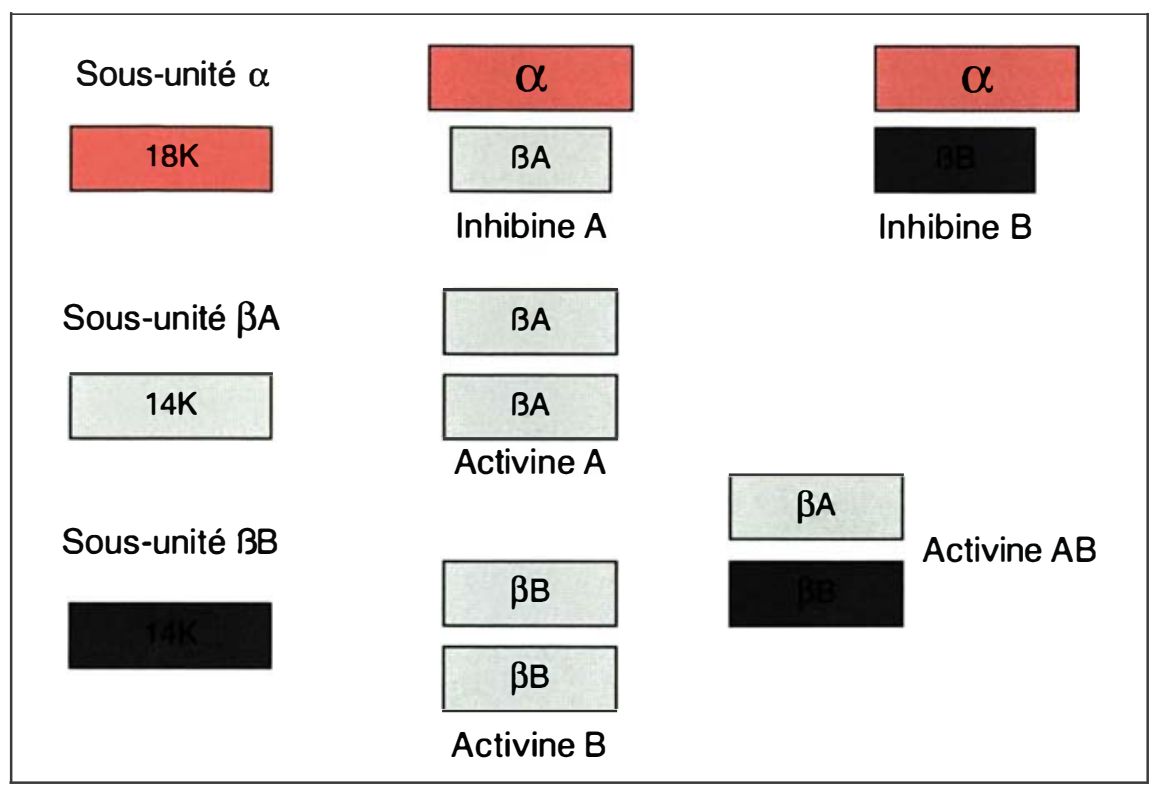

Figure 6. Structure de l'inhibine et de l'activine. Trois gènes codant pour des précurseurs des sous-unités de l'inhibine ont été isolés, un pour la sous-unité $\alpha$ et deux pour la sous-unité $\beta, \beta_{A}$ et $\beta_{B}$ dont les produits ont environ $85 \%$ $d^{\prime}$ analogie. Il existe donc deux formes d'inhibine $\alpha \beta_{A}$ et $\alpha \beta_{B}$ possédant une activité biologique identique. L'activine est un dimère des sous-unités $\beta$ de l'inhibine. II en existe trois formes, l'activine $A\left(\beta_{A} \beta_{A}\right)$, l'activine $A B\left(\beta_{A} \beta_{B}\right)$, et l'activine $B\left(\beta_{B} \beta_{B}\right)$.

que de l'inhibine pose encore de nombreux problèmes.

L'inhibine a été purifiée initialement à partir de liquide folliculaire ovarien où se déversent les produits de sécrétion des cellules de la granulosa. Dans le testicule, l'inhibine est produite essentiellement par les homologues des cellules de la granulosa, les cellules de Sertoli [29]. Les cellules de Leydig expriment, elles aussi, les gènes codant pour toutes les sous-unités de l'inhibine, mais, chez l'adulte, leur contribution à la sécrétion globale d'inhibine est faible, de même que celle des sources extra-gonadiques de l'hormone [30].

Fait étonnant, chez le rat, l'expression des gènes codant pour toutes les sous-unités de l'inhibine prédomine dans le testicule immature et diminue au cours du développement [31]. Au contraire, dans le sérum humain, la concentration d'inhibine, élevée au cours de la première année de vie [32], diminue ensuite pour s'élever à nouveau au moment de la puberté [7].

La propriété essentielle de l'inhibine, celle qui lui a donné son nom et qui a conduit à son isolement en 1985 par une équipe australienne [33], est sa capacité d'inhiber la synthèse de la FSH hypophysaire. L'existence d'un inhibiteur testiculaire non stéroïdien de la sécrétion de FSH avait été décrite dès 1932, mais il fallut attendre 1982 pour localiser de façon indiscutable sa production aux cellules de Sertoli [34]. L'action de l'inhibine sur la sécrétion de FSH hypophysaire exige au moins 24 heures, et passe en partie par la déstabilisation de son messager ; la sécrétion de LH n'est pas affectée (voir [35] pour revue). Outre son effet endocrine proprement dit, l'inhibine potentialise l'effet de la LH sur la production d'androgènes [36] et pourrait exercer d'autres effets paracrines ou autocrines. La survenue de tumeurs du stroma ovarien chez des souris dont le gène codant pour la sous-unité $\alpha$ de l'inhibine a été inactivé [37] suggère que l'inhibine pourrait jouer un rôle antitumoral dans le tissu gonadique $\left(m / s n^{\circ} 1\right.$, vol. 9, p. 100). La surexpression d'activine pourrait également être impliquée [38].

Le régulateur majeur de la sécrétion de l'inhibine par les cellules de Sertoli est la FSH, agissant par l'intermé- 


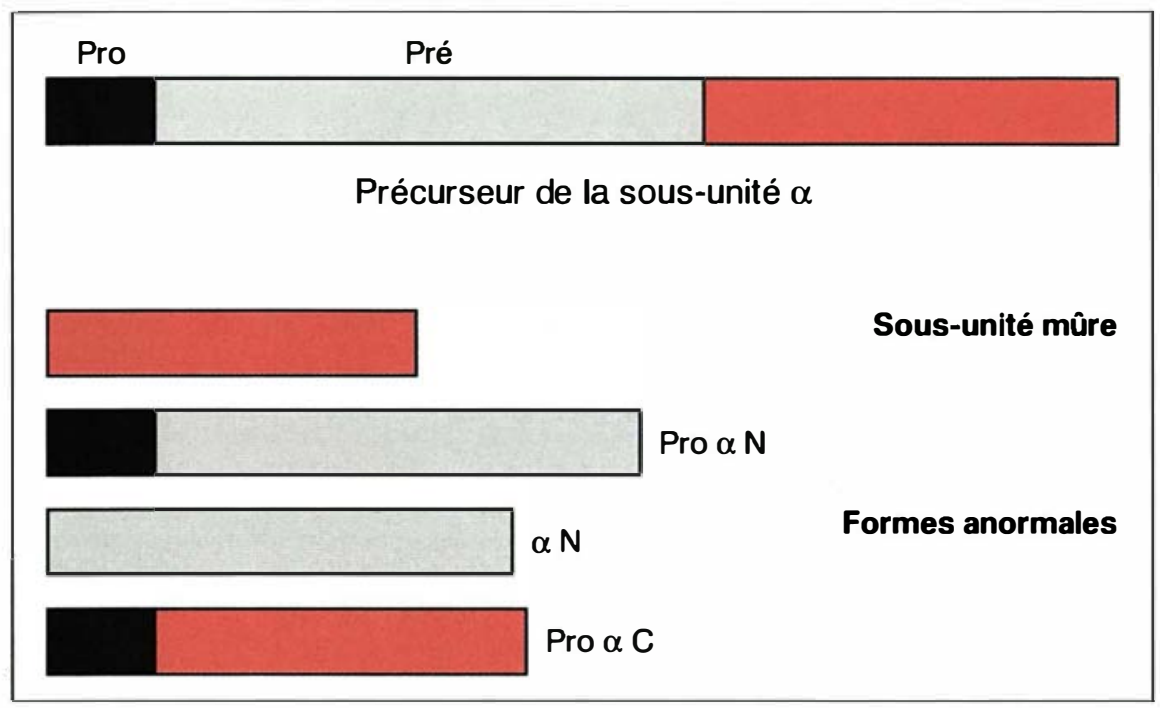

Figure 7. Formes aberrantes de la sous-unité $\alpha$ de l'inhibine. Normalement, la sous-unité $\alpha$ subit deux clivages protéolytiques, détachant le peptide signal (fragment pro), puis le fragment $N$-terminal (fragment pre) pour libérer le fragment $C$-terminal mature. Les sous-unités pro- $\alpha N, \alpha N$ et pro-aC qui ont subi des clivages aberrants, ont une activité biologique qui diffère de celle de l'inhibine mais réagissent avec les anticorps dirigés contre elle.

diaire de récepteurs membranaires. Dans des cellules de Sertoli isolées en culture, le traitement par la FSH augmente de façon significative l'expression de la sous-unité $\alpha$ [31] mais pas celle des sous-unités $\beta$ [39] ; la testostérone est sans effet. In vivo, le traitement par la testostérone ou par hCG augmente la concentration sérique de l'inhibine. Cela peut s'expliquer par les interactions entre les différents types cellulaires. Les cellules péri-tubulaires synthétisent un facteur paracrine, PModS, réglé par la testostérone, qui module la fonction des cellules de Sertoli, et stimule, en particulier, leur sécrétion d'inhibine [40]. Certains types de cellules germinales ont également un effet favorisant sur la production d'inhibine par les cellules de Sertoli [41].

\section{L'activine}

C'est un dimère des sous-unités $\beta$ de l'inhibine (figure 6). Il en existe trois formes, l'activine $A\left(\beta_{A} \beta_{A}\right)$, l'activine $\mathrm{AB}\left(\beta_{\mathrm{A}} \beta_{\mathrm{B}}\right)$, et l'activine $\mathrm{B}\left(\beta_{\mathrm{B}} \beta_{\mathrm{B}}\right)$; cette dernière vient seulement d'être isolée d'une source naturelle. Exprimant la sous-unité $\alpha$ en excès, le testicule produit assez peu de dimères $\beta$ rimentales, la concentration de $\mathrm{LH}$ n'est pas affectée, mais l'activine inhibe la sécrétion basale d'hormone de croissance et d'ACTH (adreno-corticotropic hormone), et exerce des eff ets paracrines sur la cellule de Sertoli, où elle annule les effets de la FSH sur l'activité aromatase et sur l'expression du récepteur des androgènes [43]. Sur les cellules de Leydig et les cellules germinales, l'activine exerce également des effets inverses de ceux de l'inhibine : elle s'oppose à l'effet de la LH sur la stéroïdogenèse des cellules de Leydig [45] et stimule la division des cellules germinales [46] et la prolifération de cellules testiculaires tumorales chez les souris déficientes en inhibine $\alpha$ [38]. Enfin, à la différence de l'inhibine, l'activine exerce des effets dans des domaines relativement éloignés de la reproduction. Elle est présente chez le jeune embryon, où elle induit la formation de mésoderme et celle de structures axiales $\left(m / s n^{\circ} 8\right.$, vol. $6, p$. 825) [47]. Elle joue un rôle actif dans l'érythropoïèse $\left(m / s n^{\circ} 6\right.$, vol. $\left.6, p .598\right)$, au point de mériter l'appellation de erythroid differentiation factor (EDF) et pourrait jouer le rôle de neurotransmetteur hypothalamique impliqué dans la sécrétion d'ocytocine et de LHRH (luteinizing hormone releasing hormone) [35].

En conclusion, la cellule de Sertoli mérite bien le titre de cellule endocrine, même si les hormones qu'elle produit jouent également un rôle local. Ces hormones ont l'avantage d'être bien définies sur le plan biochimique et moléculaire, ce qui les distingue des nombreux "facteurs" testiculaires qui vont et viennent dans la littérature. Pourtant, la complexité de l'environnement testiculaire, les nombreuses interactions entre les différents compartiments cellulaires laissent subsister encore des inconnues, en particulier en ce qui concerne leur mode d'action. De façon plus prosaïque, le dosage sérique de l'AMH et de l'inhibine permet actuellement d'explorer la valeur fonctionnelle des tubes séminifères avant et après la puberté, ce qui présente un intérêt clinique non négligeable

\section{TIRÉS À PART}

N. Josso. 


\section{Summary}

The Sertoli cell, an endocrine cell

The coordinated interaction of the different cell types existing within the testis results in the implementation of masculinity and fertility. Sertoli cells have long been described as sustencular cells of the seminiferous tubules. Additional functions have successively been discovered. Sertoli cells are responsible for the development of the blood-testis barrier during pubertal maturation and have also a well developed secretory function. Some secretory products play a role within the testis as paracrine factors. However, Sertoli cells also produce proteins which exert their action on distant target cells, i.e. they act as hormones. The endocrine activity of Sertoli cells varies with their degree of maturation. Very early in fetal development, Sertoli cells begin to secrete anti-Müllerian hormone $(\mathrm{AMH})$, also called Müllerian inhibiting substance (MIS) or factor (MIF), a $140 \mathrm{kD}$ homodimeric glycoprotein responsible for the regression of Müllerian ducts, which give rise to Fallopian tubes, uterus and upper part of the vagina in the female. Sertoli cells secrete AMH in high amounts from the moment of testicular differentiation until puberty, when AMH production declines to very low or un- detectable levels. AMH is secreted by Sertoli cells as a pro-hormone, and its C-terminal fragment must be cleaved to be biologically active. Transcription of AMH in the immature Sertoli cell is activated by the orphan nuclear receptor SF-1 (steroidogenic factor 1), which could act as a mediator between the testis determining factor SRY and AMH expression. During puberty, AMH production is negatively regulated by testosterone. Due to the persistence of AMH expression after Müllerian duct regression in the male and during reproductive life in the female, many other physiological roles have been proposed for AMH within the gonads, where its receptor has been identified. As it inhibits aromatase activity, AMH could be important for testicular differentiation in the fetus and enhance gonocyte proliferation after birth. An inhibitory role of $\mathrm{AMH}$ on steroidogenesis has been suggested by the fact that transgenic mice over expressing $\mathrm{AMH}$ are incompletely masculinised, while mice in whom the $A M H$ gene was inactivated develop Leydig cell hyperplasia. Apart from AMH secretion, Sertoli cells are capable of producing androgens from Leydig steroid precursors and show an active aromatase activity, which declines with cell maturation. The endocrine activity of adult Sertoli cells is dominated by the secretion of inhibin and activin, which are, like $\mathrm{AMH}$, members of the TGF- $\beta$ family. In the testis, these peptides are also produced by Leydig cells. As a consequence of the higher expression of the $\alpha$-subunit as compared with that of $\beta$-subunits of inhibin, Sertoli cells secrete much more inhibin (an $\alpha-\beta$ heterodimer) than activin (a $\beta-\beta$ homodimer). Sertoli cell secretion of inhibin is activated by FSH. The resulting increment of inhibin serum levels exerts a negative feedback, thus inducing a decrease of pituitary secretion of FSH. Locally, inhibin potentiates $\mathrm{LH}$ stimulation of androgen synthesis. The action of activin is opposed to that of inhibin: it stimulates pituitary FSH secretion and inhibits LH stimulation of steroidogenesis. Activin also has effects out of the reproductive tract: it induces axial mesodermal structures and has an active role in erythropoiesis. Both AMH and inhibin can be assayed in human serum, allowing an assessment of the functional value of the Sertoli cells both before and after puberty. 